University of Wollongong

Research Online

Faculty of Engineering and Information

Faculty of Engineering and Information

Sciences - Papers: Part B

Sciences

2018

\title{
Influence of a health technology assessment on the use of pediatric cochlear implantation in Kazakhstan
}

Lyazzat Kosherbayeva

Asfendiyarov Kazakh National Medical University, lyazzat.k@mail.ru

Aigul Medeulova

Asfendiyarov Kazakh National Medical University

David M. Hailey

University of Wollongong, dhailey@uow.edu.au

Lyudmila Yermukhanova

West Kazakhstan Marat Ospanov State Medical University

Raisa Uraz

West Kazakhstan Marat Ospanov State Medical University

See next page for additional authors

Follow this and additional works at: https://ro.uow.edu.au/eispapers1

Part of the Engineering Commons, and the Science and Technology Studies Commons

Research Online is the open access institutional repository for the University of Wollongong. For further information contact the UOW Library: research-pubs@uow.edu.au 


\title{
Influence of a health technology assessment on the use of pediatric cochlear implantation in Kazakhstan
}

\author{
Abstract \\ 2018 Fellowship of Postgraduate Medicine Objective: To evaluate the influence of a health technology \\ assessment (HTA) on pediatric cochlear implantation $(\mathrm{Cl})$ in Kazakhstan and to provide a further \\ perspective on the use of the technology in that country. Ideally, children should be implanted as young as \\ possible, have adequate rehabilitation, and be integrated into the regular school system. Methods: \\ Administrative data for 2013-2016 relevant to pediatric $\mathrm{Cl}$ in Kazakhstan were obtained from the Ministry \\ of Health and from a survey of authorities in the 16 regions of the country. The data were compared with \\ those for 2007-2012 used in preparation of the HTA report. Results: Funding continued to be available \\ only for unilateral $\mathrm{Cl}$, a clinical protocol for the procedure was finalized and availability of equipment for \\ audiological screening had improved considerably. In Kazakhstan the proportion of children over 5 years \\ old at implantation had decreased by $65 \%$, while that for children less than 2 years old had increased from \\ 12 to $35 \%$. Rehabilitation of children post-implantation was limited by the small numbers of suitable \\ specialists. There was an increase in numbers of children enrolled in schools for those with moderate or \\ profound hearing impairment. The number of children educated in standard schools remains low. \\ Conclusion: The HTA made a useful contribution to the development of cochlear implantation services in \\ Kazakhstan. The shortage of specialists for provision of rehabilitation and the limited placement of \\ implanted children in general schools are matters for government decision - makers to consider.

\section{Disciplines} \\ Engineering | Science and Technology Studies

\section{Publication Details} \\ Kosherbayeva, L., Medeulova, A., Hailey, D., Yermukhanova, L., Uraz, R. \& Aitmanbetova, A. (2018). \\ Influence of a health technology assessment on the use of pediatric cochlear implantation in Kazakhstan. \\ Health Policy and Technology, Online first 1-4.

\section{Authors} \\ Lyazzat Kosherbayeva, Aigul Medeulova, David M. Hailey, Lyudmila Yermukhanova, Raisa Uraz, and \\ Akmaral Aitmanbetova
}




\section{Cover letter}

Title:

Influence of a health technology assessment on the use of pediatric cochlear implantation in Kazakhstan

\section{Short title: Cochlear implantation in Kazakhstan}

\section{Corresponding author:}

Lyazzat Kosherbayeva

« Kazakh National Medical University named after S. Asfendiyarov»

90 Tole bi Str,

Almaty, Kazakhstan

Telephone: +77778824698

Lyazzat.k@mail.ru

Funding: Financial support for this project was not sought from any external funding body or commercial organization 


\section{Title page}

\section{Title:}

Influence of a health technology assessment on the use of pediatric cochlear implantation in Kazakhstan

\section{Short title: Cochlear implantation in Kazakhstan}

\section{Authors}

PhD Lyazzat Kosherbayeva, ${ }^{1,5}$, Aigul Medeulova ${ }^{1,2}, \mathrm{PhD}$ David Hailey ${ }^{3}$, PhD Lyudmila Yermukhanova $^{4}$, Raisa $\mathrm{Uraz}^{4}, \mathrm{PhD}$ Akmaral Aitmanbetova ${ }^{1}$

${ }^{1}$ Kazakh National Medical University, Kazakhstan

${ }^{2}$ High School of public health, Kazakhstan

${ }^{3}$ University of Wollongong, Australia

${ }^{4}$ Marat Ospanov West Kazakhstan State Medical University

${ }^{5}$ Al Farabi named Kazakh National University, Kazakhstan

* Corresponding author:

Lyazzat Kosherbayeva

«Kazakh National Medical University named after S. Asfendiyarov»

90 Tole bi Str,

Almaty, Kazakhstan

Telephone: +77778824698

Lyazzat.k@mail.ru

Funding: Financial support for this project was not sought from any external funding body or commercial organization

Keywords: Health technology assessment; Cochlear implantation, Children, Kazakhstan. 


\section{Abstract}

Objective: To evaluate the influence of a health technology assessment on pediatric cochlear implantation (CI) in the Republic of Kazakhstan and to provide a further perspective on the use of the technology in that country.

Methods: Administrative data for 2013 - 2016 relevant to pediatric CI in Kazakhstan were obtained from the Ministry of Health and from a survey of authorities in the 16 regions of the country. The data were compared with those for 2007 - 2012 used in preparation of the health technology assessment report.

Results: Funding continued to be available only for unilateral CI, a clinical protocol for the procedure was finalized and availability of equipment for audiological screening had improved considerably. Ideally, children should be implanted as young as possible, have adequate rehabilitation, and integrated into the regular school system. In Kazakhstan the proportion of children over 5 years old at implantation had decreased by 65 percent, while that for children less than 2 years old had increased from 12 to 35 percent. Rehabilitation of children post-implantation was limited by the small numbers of suitable specialists. There was an increase in numbers of children enrolled in schools for those with moderate or profound hearing impairment. The number of children educated in standard schools remains low..

Conclusion: The health technology assessment made a useful contribution to the development of cochlear implantation services in Kazakhstan. The shortage of specialists for provision of rehabilitation and the limited placement of implanted children in general schools are matters for government decision - makers to consider. 


\section{INTRODUCTION}

Cochlear implantation (CI) is the standard for treatment of children with sensorineural hearing loss which occurs when there is damage to the hair cells in the inner ear or to the nerve pathways that lead from the inner ear to the brain. Sensorineural hearing loss is permanent and both decreases the ability to hear weak sounds, and the understanding and perception of speech. CI provides such children with the sensation of hearing and improves their speech development, perception, production and spoken language development (1). The effective use of CI in children is associated with identification of candidates for implantation through audiological screening, and extended rehabilitation following the procedure. Early screening and intervention are recommended (2,3), and implantation has been performed on children who are less than 12 months old $(4,5,6$,).

In the Republic of Kazakhstan, a program on cochlear implantation was started in 2007. The State Benefit Package, which provides free medical assistance for Kazakhstan citizens, covered only unilateral CI. Bilateral CI could be done if requested, but the patient would have to pay additional expenses incurred due to the second implant. The Ministry of Health of the Republic of Kazakhstan $(\mathrm{MoH})$ had been asked whether bilateral $\mathrm{CI}$ in children should also be covered under the State Benefit Package. To help address this issue, in 2012, a health technology assessment (HTA) report for the $\mathrm{MoH}$ provided advice on the effectiveness of uni- and bilateral $\mathrm{CI}$ in children and issues associated with the provision of CI in Kazakhstan. These included the availability of audiological screening and rehabilitation services, ages of implantation since introduction of the program, the need for standard protocols, and the education of children who had received an implant. (7,8). The assessment considered relevant literature for the period 2002-2012, and administrative data on hearing loss in children and the use of CI in Kazakhstan that were obtained from the MoH. Details of schooling arrangements for the children who had received implants were obtained from the hospitals that performed the surgery.

The assessment found that there was no consensus on the status of bilateral $\mathrm{CI}$ in children. The quality of the available studies was poor and there was little information on longer- term outcomes. No conclusions could be drawn regarding later incremental improvements to speech perception, learning, and quality of life. $(4,8)$. A cost analysis found that the per patient cost in Kazakhstan for unilateral implantation was the equivalent of \$US 14,030 and an additional \$US 13,130 for simultaneous bilateral implantation. In Kazakhstan, there was limited availability of audiology equipment to provide timely screening, which led to the loss of early identification of children with hearing impairment. In addition, CI was undertaken at later ages than were now accepted in international practice. During discussion with clinical experts during preparation of the report it became apparent 
that in Kazakhstan there were many differences between centres in their approaches to audiological screening, implantation and rehabilitation. In general, there was a lack of common standards, in part due to differences in the availability of trained audiologists and speech therapists and of appropriate equipment. Only small numbers of children with implants (38 of 460) attended general education schools $(7,8)$.

The HTA report concluded that there appeared to be other priorities for improving services for children with profound hearing impairment than supporting bilateral implantation. It suggested expanding the coverage of screening services, providing early implantation, and improving rehabilitation services to increase the participation of children with implants in the general school system. Bilateral CI might be an option for the future as further evidence became available and the implantation services in Kazakhstan matured (8). Development of protocols of clinical practice for CI would serve as the basis for a unified approach with better communication and optimization of resources for all organizations involved in this area $(7,8)$. These include centres providing screening, surgical and rehabilitation services, different government ministries with involvement in the CI program, schools, and non-government organizations founded by parents of children with CI. Lack of uniform protocols can lead to a fragmented process in which it is easy to lose track of patients who need a CI and of those who have been implanted.

The HTA report was accepted by the $\mathrm{MoH}$ which decided not to support the provision of bilateral CI. A major consideration would have been the need to improve existing CI and associated services as a priority before committing resources to new technology. The uncertain clinical effectiveness of bilateral CI may also have been a factor (8).

Action was to be taken to procure equipment for the early detection of children with sensorineural hearing loss, and to strengthen rehabilitation services after CI. A centre within the MoH started to coordinate work on the development of protocols on $\mathrm{CI}$ in conjunction with clinical experts and other health professionals (8).

The purpose of the study reported here was to assess the further influence of the health technology assessment report on and to provide an update on use of CI in the Republic of Kazakhstan for children with sensorineural hearing loss.

\section{METHODS}

Advice on the status of support for pediatric CI through the State Benefit Package was obtained from the $\mathrm{MoH}$. Progress in the preparation at a national level of a protocol for children with sensorineural hearing loss was checked with the Republican Center for Health Development.

Administrative data and decisions from 2013 to 2016 relevant to performance of CI for children in Kazakhstan were obtained from through a survey of health authorities in the 16 regions of the 
country. The request for information and survey forms were sent through the $\mathrm{MoH}$, which oversees the regions. Information was requested on numbers of children who had received CI; availability of equipment for audiological screening in medical organizations and health centres; numbers of audiologists and speech therapists in the region; types of schooling received by children with CI; and numbers of children with hearing loss who were identified through audiological screening.

\section{RESULTS}

Responses had continued to several recommendations made in the 2013 report following its release.. Funding through the State Benefit Package was still available only for unilateral cochlear implantation and not for bilateral procedures. The clinical protocol for CI was finalized by the Republican Center in December 2014 (9), made available to stakeholders by website, and disseminated to all regional specialists. The clinical protocol is approved at the level of the $\mathrm{MoH}$ and all medical assistance activities should meet its requirements. The protocol included a list of basic and additional diagnostic measures, the purpose of the procedure, indications and contraindications, , requirements for the patient's preparation for surgery, the operative procedure and indicators of the effectiveness and safety of diagnostic and treatment methods.

Audiological screening is used to identify patients with hearing loss (in newborns it is carried out in the maternity ward). Equipment required includes otoacoustic emissions and auditory brainstem response technologies (10). Availability of equipment for audiological screening for period was improved considerably from 2012 to 2017 following provision of funding for purchase by local health departments. Information obtained from the regions indicated that in 13 all relevant medical organizations were suitably equipped to provide audiological screening. The proportions of equipped medical organizations in two regions were 91 percent and 72 percent. The other region indicated that its organization was equipped but did not clarify whether fully or not. In comparison, the 2012 report found that only 29 percent of medical organizations had audiology equipment. (7).

Numbers of children diagnosed with neurosensorial deafness from 2012 to 2017 are shown in Table 1. A majority (58 percent) had bilateral hearing impairment. Those identified through screening included children who were less than one year old, but most (74 percent) were in older age groups between 5 and 18 .

The number of implantations per year from 2013 to 2016 was of the same order as that performed previously, with a small decrease (142 per year compared to 159 per year. As shown in Table 2 there had been substantial changes from previous years in the age of implantation. The proportion of children over 5 years old at implantation had decreased by 65 percent. More than a third 
of the children were less than 2 years old at implantation, an increase from 12 percent between 2007 and 2012.

Developments for rehabilitation of children post-implantation have been limited, in part, because of small number of suitable specialists. Information was available from 13 of the 16 regions. In 12 of these there were 19 audiologists and 34 speech therapists, with varying work experience and few with graduate qualifications (Table 3). The other region did not have such specialists. Those are limited resources, given the realities for provision of a routine service when absence due to leave and other commitments are taken into account. This shortage of health professionals seems applicable throughout the country, though there may also be additional difficulties in recruitment for rural locations. These data do not include specialists from private clinics, who may be available for such work in some regions. Parents who do not want to wait for free medical care can get services in private clinics, but this is rarely practiced.

There have been some changes in provision of education to children with cochlear implants. Information on schooling was available for 460 of 664 children with implants for the 2012 report and for 748 in the 2016 survey. The proportions of children in different types of schooling are shown in Table 4. The number of children educated in standard schools remains very low, and the proportion had decreased since 2012. The proportion educated at home had also decreased, while there had been a substantial increase in numbers of children who were enrolled in schools or kindergartens for those with moderate or profound hearing impairment. This indicates the further availability of specialized educational organizations for children with CI.

\section{DISCUSSION}

The information from this study gives indications of the influence of advice from the 2012 HTA report, and of developments in the provision of CI services to children in Kazakhstan.

There is a progression of possible influence of health technology assessment, from the increased knowledge and awareness at the decision-maker level, to changes in policy and healthcare delivery, and then to changes in patient outcomes. (11). The HTA report had some influence on the first two of these through advising decision-makers about CI and on audiology services in Kazakhstan. This advice was reflected in the continuation of funding only for unilateral CI, increased availability of equipment for audiological screening, and the development of a practice protocol. The report may also have contributed to the reduction in the age of implantation for children with sensorineural hearing loss, though that would probably also have been influenced through discussion by clinical and other decision-makers. Changes to health care and improved health are dependent on the actions of many individuals and organizations (11).

Other findings from the study indicate the desirability of further consideration of arrangements for providing CI to children in Kazakhstan. With the wider availability of audiological screening 
equipment, many children with sensorineural hearing loss were identified from 2013 to 2016. The large majority were over five years old, raising further issues for decision - makers. How should this 'backlog' of older candidates for CI be managed? Should priority for CI still be given to children in younger age groups? Recent work in the USA on the achievements of 83 older children in the years following implantation found that some children who received cochlear implants between the ages of 2 and 4 years had the capacity to approximate the language and reading skills of their earlier-implanted peers (13). This suggested that additional factors may moderate the influence of age at implantation on outcomes over time. It is worthwhile to think about providing specialists who will deal with children after $\mathrm{CI}$ in order to further such achievements.

The 2012 report may have contributed to decisions on the changes in numbers of children in special schooling and those being schooled at home, but there would have been other factors. It had no obvious influence on the availability of audiological specialists in different regions, which remains a problem that may require the attention of decision - makers in more than one government organization.

Increasing the proportion of implanted children who attend general schools will be a longerterm task, beyond the scope of a single assessment. Strengthening the monitoring of children in educational activities would require involvement of the Ministry of Education, which has responsibility for educational organizations, as well as the MoH. In the State program "Densaulyk" for 2016-2019, which covers legislative and administrative arrangements, the first priority area is to strengthen public health and intersectoral cooperation (12).

Our study had some limitations, being based mainly on administrative data with little opportunity for input from decision-makers on how services were provided. Some regions were unable to provide complete data, and information on audiologists and speech therapists who work in private clinics was not available. Further monitoring and evaluation of pediatric CI and associated services is necessary. It would also be useful for governmental and clinical decision - makers in Kazakhstan to be kept informed of any further evidence on the effectiveness of bilateral CI in children.

\section{CONCLUSION}

The 2013 HTA report provided advice on pediatric CI that was helpful to decision makers. Presented recommendations of the report allowed improvements in audiological screening and lowering the age of implantation, and also initiated the development of a clinical protocol, which standardizes the process. The changes in policy had potentially beneficial impacts on the population of hearing impaired children in Kazakhstan. Further efforts are needed to address requirements for rehabilitation and placement of children with implants in standard schools.

\section{Acknowledgements}


We are grateful to the Ministry of Health of the Republic of Kazakhstan and to regional representatives of the Health Department for their assistance in collecting information.

Funding: Financial support for this project was not sought from any external funding body or commercial organization

Conflict of interest: Authors disclose there is no conflict of interest

Ethics statement: The study approved by the local ethics committee of Marat Ospanov named West Kazakhstan State Medical University

\section{REFERENCES}

1.) Yoon PJ. Pediatric cochlear implantation. Curr Opin Pediatr. 2011 Jun;23(3):346-50. doi: 10.1097/MOP.0b013e32834618ec. https://www.ncbi.nlm.nih.gov/pubmed/21572386

2.) Tobey EA, Thal D, Niparko JK, Eisenberg LS, Quittner AL, Wang N-Y Influence of implantation age on school-age language performance in pediatric cochlear implant users Int J Audiol 2013; 52(4): 219-229.. doi: $10.3109 / 14992027.2012 .759666$

3.) Leigh JR, Dettman SJ, Dowell RC. Evidence-based guidelines for recommending cochlear implantation for young children: Audiological criteria and optimizing age at implantation. Int J Audiol. 2016;55 Suppl 2:S9-S18. doi: 10.3109/14992027.2016.1157268. Epub 2016 May 4. https://www.ncbi.nlm.nih.gov/pubmed/27142630

4.) Cosetti M, Roland JT Jr. Cochlear implantation in the very young child: issues unique to the under-1 population. Trends Amplif. 2010 Mar;14(1):46-57. doi: 10.1177/1084713810370039. https://www.ncbi.nlm.nih.gov/pubmed/20483813

5.) Dettman SJ., Pinder D., Briggs RJ., Dowell RC., Leigh JR. Communication development in children who receive the cochlear implant younger than 12 months: risks versus benefits. Ear Hear. 2007 Apr;28(2 Suppl):11S-18S. https://www.ncbi.nlm.nih.gov/pubmed/17496638

6.) McKinney S. Cochlear implantation in children under 12 months of age. Curr Opin Otolaryngol Head Neck Surg. 2017 Oct;25(5):400-404. doi: 10.1097/MOO.000000000000040

7.) Kosherbayeva L, Hailey D. Bilateral and unilateral cochlear implantation in children. Astana: Ministry of Public Health of the Republic of Kazakhstan; 2013.

8.) Kosherbayeva L, Hailey D, Kozhageldiyeva L. Rapid assessment of bilateral cochlear implantation for children in Kazakhstan. Int J Technol Assess Health Care, 2014; 30 (4), 361-365.

9.) Clinical protocol for diagnosis and treatment of bilateral sensorineural hearing loss. Recommended Expert Council Republican Center for health development, Ministry of Health and Social Development Republic of Kazakhstan. December 12, 2014, Protocol No. 9 (in Russian) 
http://www.rcrz.kz/docs/clinic_protocol/2014/Педиатрия/Сурдология/Двусторонняя нейросенсорная тугоухость.pdf

10.) American Speech-Language-Hearing Association. Permanent Childhood Hearing Loss.

Assessment. Available https://www.asha.org/Practice-Portal/Clinical-Topics/Permanent-Childhood-

Hearing-Loss/

11.) Hailey D, Werkö S, Rosén M, et al. Influence of health technology assessment and its measurement. Int J Technol Assess Health Care 2016: 32 (6 ): 376-384. DOI:

https://doi.org/10.1017/S0266462316000611

12.) State Program №176 «Densaulyk for 2016-2019» on Introduction of amendments and supplements to the decree of the President of the Republic of Kazakhstan, January 15, 2016. P.23-30. http://mz.gov.kz/sites/default/files/gprz_ru.pdf (in Russian)

13.) Dunn CC, Walker EA, Oleson J, et al. , (2014) Longitudinal speech perception and languae performance in pediatric cochlear implant users: the effect of age at implantation. Ear Hear. 2014; 35(2): 148-160. doi: 10.1097/AUD.0b013e3182a4a8fo

Table 1. Numbers of children diagnosed with sensorineural deafness

\begin{tabular}{|l|c|c|c|c|c|c|c|c|c|}
\hline & \multicolumn{5}{|c|}{ Unilateral } & \multicolumn{5}{c|}{ Bilateral } & $\begin{array}{c}\text { Year } \\
\text { totals }\end{array}$ \\
\hline & $\begin{array}{c}< \\
\text { year }\end{array}$ & $\begin{array}{c}1-4 \\
\text { years }\end{array}$ & $\begin{array}{c}5-18 \\
\text { years }\end{array}$ & Total & $\begin{array}{c}<1 \\
\text { year }\end{array}$ & $\begin{array}{c}1-4 \\
\text { years }\end{array}$ & $\begin{array}{c}5-18 \\
\text { years }\end{array}$ & Total & \\
\hline 2013 & 39 & 63 & 303 & 405 & 81 & 130 & 449 & 660 & 1065 \\
\hline 2014 & 46 & 104 & 861 & 1011 & 89 & 173 & 611 & 873 & 1884 \\
\hline 2015 & 52 & 162 & 476 & 690 & 96 & 180 & 634 & 910 & 1600 \\
\hline 2016 & 20 & 84 & 390 & 494 & 78 & 190 & 884 & 1152 & 1646 \\
\hline$\therefore$ & & & & & & & & \\
\hline
\end{tabular}




\begin{tabular}{|l|c|c|c|c|c|c|c|c|c|c|c|c|c|}
\hline Table 2: Numbers, by age, of children receiving CI in Kazakhstan \\
\hline Age, years & \multicolumn{2}{|c|}{$0-1$} & \multicolumn{2}{|c|}{$1-2$} & \multicolumn{2}{|c|}{$2-3$} & \multicolumn{2}{|c|}{$3-4$} & \multicolumn{2}{|c|}{$4-5$} & \multicolumn{2}{|c|}{$>5$} \\
\cline { 2 - 13 } & $\mathrm{n}$ & $\%$ & $\mathrm{n}$ & $\%$ & $\mathrm{n}$ & $\%$ & $\mathrm{n}$ & $\%$ & $\mathrm{n}$ & $\%$ & $\mathrm{n}$ & $\%$ \\
\hline $2007-2012$ & 26 & 4 & 52 & 8 & 76 & 12 & 96 & 15 & 76 & 12 & 306 & 48 \\
& & & & & & & & & & & & \\
\hline $2013-2016$ & 62 & 11 & 136 & 24 & 85 & 15 & 97 & 17 & 91 & 16 & 97 & 17 \\
& & & & & & & & & & & & \\
\hline
\end{tabular}


Table 3: Numbers of specialist staff available in 12 regions

\begin{tabular}{|l|l|c|c|l|l|}
\hline & \multicolumn{3}{|l|}{ Work experience } & \\
& $1-5$ & $6-10$ & $11-15$ & Up to 15 & $\begin{array}{c}\text { Have a } \\
\text { scientific } \\
\text { years } \\
\text { degree }\end{array}$ \\
\hline Audiologists & 7 & 5 & 3 & 4 & 5 \\
\hline Speech therapists & 10 & 3 & 3 & 18 & 1 \\
\hline
\end{tabular}


Table 4: Types of schooling for children with cochlear implants

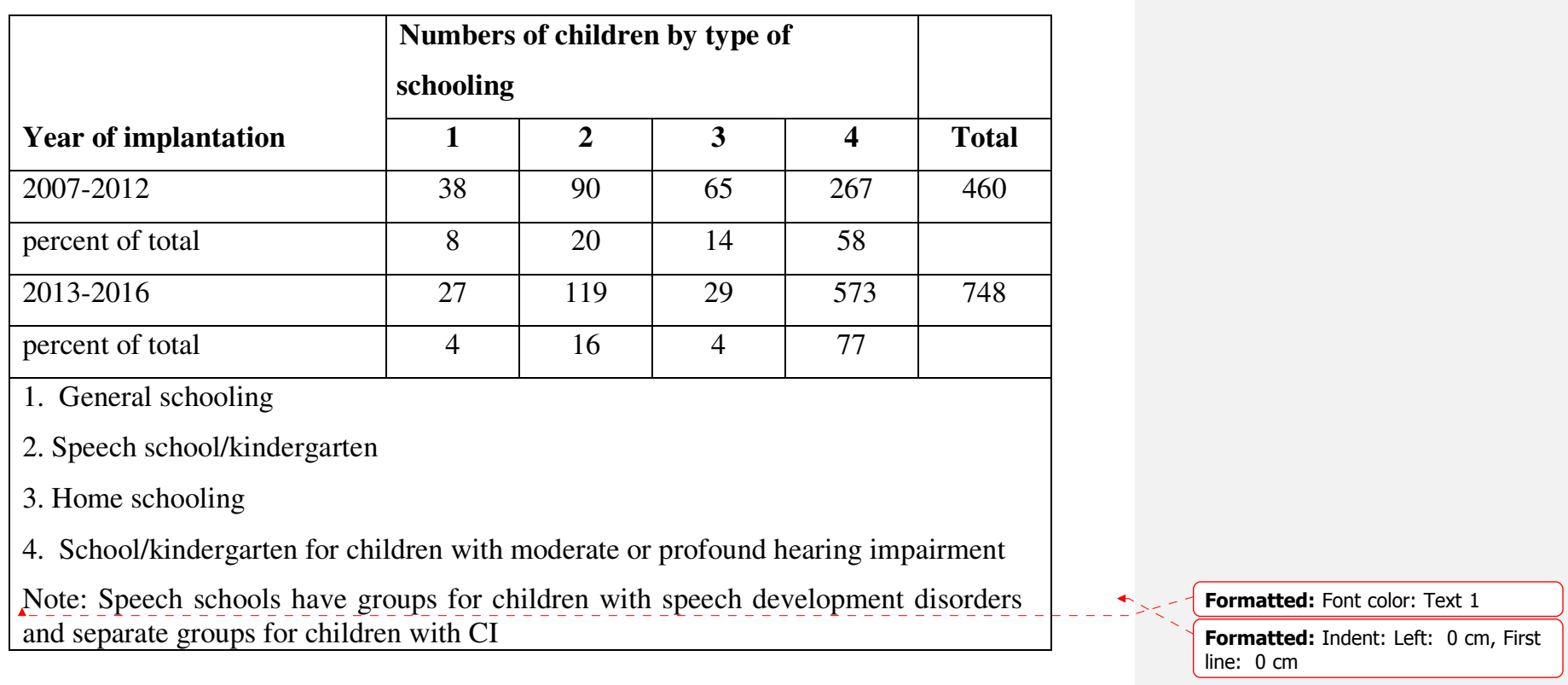

